\title{
Intergranular film analyses in $\alpha$-SiC sintered with Al-additives
}

\author{
M.-L. DUVAL-RIVIERE and J. VICENS
}

LERMAT, URA 1317 du CNRS, ISMRA, 6 bd du Maréchal Juin, 14050 Caen cedex, France

\begin{abstract}
HREM and EDS microanalyses were performed on two grades of hotpressed $\alpha-\operatorname{SiC}(0.3 \mathrm{wt} \%$ and $1.5 \mathrm{wt} \%$ Al additives) in the as-sintered state and also after annealing treatments and creep tests in the temperature range $1600-1950^{\circ} \mathrm{C}$. An amorphous aluminosilicate film ( $1 \mathrm{~nm}$ thick) was imaged in grain boundaries of all samples except for the one deformed by three point bending at $1600^{\circ} \mathrm{C}$ which exhibits only a small amount of $A 1$ and $O$ intergranular segregation.
\end{abstract}

\section{INTRODUCTION}

The behaviour of polycrystalline ceramics depends on the structure and chemistry of grain boundaries. Many ceramics containing SiC materials are prepared with sintering aids which may contain $B, C$ or $A l$ based additives. A lot of studies has been devoted to detect intergranular segregation and amorphous film at SiC-SiC grain boundaries (g.b.) by using different experimental procedures (Auger spectroscopy, transmission electron microscopy (TEM), energy dispersive $X$-ray spectrometry (EDS)] [1 to 7]. Thus an intergranular Al segregation was observed by $X$-ray microanalysis in hot-pressed Al-doped SiC but TEM observations do not reveal any intergranular film [5]. By contrast an amorphous intergranular film $(1.5 \mathrm{~nm}$ thick) was recently imaged in SiC materials sintered with $\mathrm{Al}_{2} \mathrm{O}_{3}$ and $\mathrm{Y}_{2} \mathrm{O}_{3}$. However grain boundaries are not wetted by using $\mathrm{AlN}+\mathrm{Y}_{2} \mathrm{O}_{3}$ sintering aids $[6,7]$.

The aim of this study is to analyse by high resolution electron microscopy (HREM) and EDS grain boundaries of hot-pressed SiC samples sintered with Al based additives after thermomechanical tests at high temperature [8].

\section{MATERIALS AND EXPERIMENTAL PROCEDURE}

Two grades of hot-pressed $\alpha$-SiC with 0.3 wt\% and 1.5 wt\%. Al additives ${ }^{*}$ were analysed in the as-sintered state and also after annealing treatments and creep tests. The high temperature deformation was performed either by three point bending tests or by compression. Materials with their experimental creep conditions are given in table 1. Macroscopic creep parameters of the specimens deformed at high temperature by compression were previously determined [8]. Slices of the different specimens were cut with a diamond saw and mechanically ground to a thickness of $80 \mu \mathrm{m}$. Discs of $3 \mathrm{~mm}$ in diameter were dimpled up to 5 $\mu \mathrm{m}$ and finally ion milled (GATAN $6 \mathrm{kV}$ ). Grain boundaries were studied by HREM (TOPCON 002B $200 \mathrm{kV}$ electron microscope equiped with a Kevex EDS microanalyser). 
Chemical analyses were performed on g.b. orientated parallel to the electron beam with a $5.9 \mathrm{~nm}$ probe diameter. Five analyses were carried out by stepping the probe along analysed g.b. (ten g.b. in each sample).

Table 1: Materials, annealing and creep conditions.

\begin{tabular}{|c|c|c|c|c|c|c|c|}
\hline \# & Materials & $T\left({ }^{\circ} \mathrm{C}\right)$ & $\sigma(\mathrm{MPa})$ & $t(h)$ & $|\varepsilon f|$ & $\frac{\mathrm{Al}}{\mathrm{Si}}$ (count ratio $\mathrm{SiC}$ grain) & $\begin{array}{c}\frac{\mathrm{Al}}{\mathrm{Si}} \text { (count ratio } \\
\text { at g.b.) }\end{array}$ \\
\hline 1 & $\begin{array}{l}0.3 \% \text { Al } \\
\text { as-sintered }\end{array}$ & - & - & - & - & 0.016 & 0.070 \\
\hline 2 & $\begin{array}{l}0.3 \% \text { Al } \\
\text { annealed }\end{array}$ & 1950 & - & $6 \mathrm{~h} 30$ & - & 0.018 & 0.066 \\
\hline 3 & $\begin{array}{l}0.3 \% \text { Al } \\
\text { compressed }\end{array}$ & 1950 & $45-55$ & $6 \mathrm{~h} 30$ & 0.428 & 0.015 & 0.064 \\
\hline 4 & $\begin{array}{l}0.3 \% \mathrm{~A} 1 \\
\text { bent }\end{array}$ & 1600 & 150 & $50 \mathrm{~h}$ & 0.015 & 0.011 & 0.015 \\
\hline 5 & $\begin{array}{l}1.5 \% \text { Al } \\
\text { annealed }\end{array}$ & 1900 & - & $1 \mathrm{~h} 30$ & - & 0.014 & 0.093 \\
\hline 6 & $\begin{array}{l}1.5 \% \text { Al } \\
\text { compressed }\end{array}$ & 1900 & $88-102$ & $1 \mathrm{~h} 30$ & 0.43 & 0.014 & 0.080 \\
\hline
\end{tabular}

\section{RESULTS}

TEM observations revealed the presence of the additive phase at triple junctions in all analysed specimens listed in Table 1 . X-ray analyses showed that it corresponds to crystallized aluminosilicate pockets containing $\mathrm{Al}_{2} \mathrm{O}_{3}$ inclusions (Figure 1). In some cases, only aluminum phase was detected at triple points and a crystallographic relationship between $A l$ and SiC could have been established when interfaces are parallel to the basal plane of the hexagonal (4H) SiC grain : (1120)sic // (110)Al and [0001]sic // [1]1] Al. Aluminum and oxygen were the main impurities found in grains and at g.b. Al/Si count ratios are given in Table 1 for samples \#1 to \#6. Al/Si count ratio is equal to 0.015 in SiC grains. This value corresponds approximately to $1 \mathrm{wt} \% \mathrm{Al}$. Al/Si count ratio at $\mathrm{g}$.b. is equal to $\sim 0.07$ except for sample \#4 deformed by threepoint bending test $\left(1600^{\circ} \mathrm{C}\right)$. In this case, a very small enhancement of Al is detected at g.b. (AI/Si $=0.015)$ compared to $\mathrm{Al} / \mathrm{Si}=0.011$ in $\mathrm{SiC}$ grains. The $0 / \mathrm{Al}$ count ratio at $\mathrm{g} . \mathrm{b}$. is estimated to be 0.2 in all specimens. In agreement with these results, HREM studies reveal the presence of an amorphous intergranular film in all samples except in sample \#4. By using the lattice imaging method in both adjacent grains, the thickness of this film could have been evaluated to be $1 \mathrm{~nm}$ in figure 2a (sample \#3) and $1.6 \mathrm{~nm}$ in figure $2 \mathrm{~b}$ (sample \#6). HREM micrographs show that this film is amorphous and is likely formed by an aluminosilicate phase. In another hand, an example of a non-wetted $\mathrm{g} . \mathrm{b}$. frequently observed in sample \#4 is shown in figure 3 with its corresponding spectrum taken at g.b. It can be also noticed that the additive phase is still present at triple junctions. 


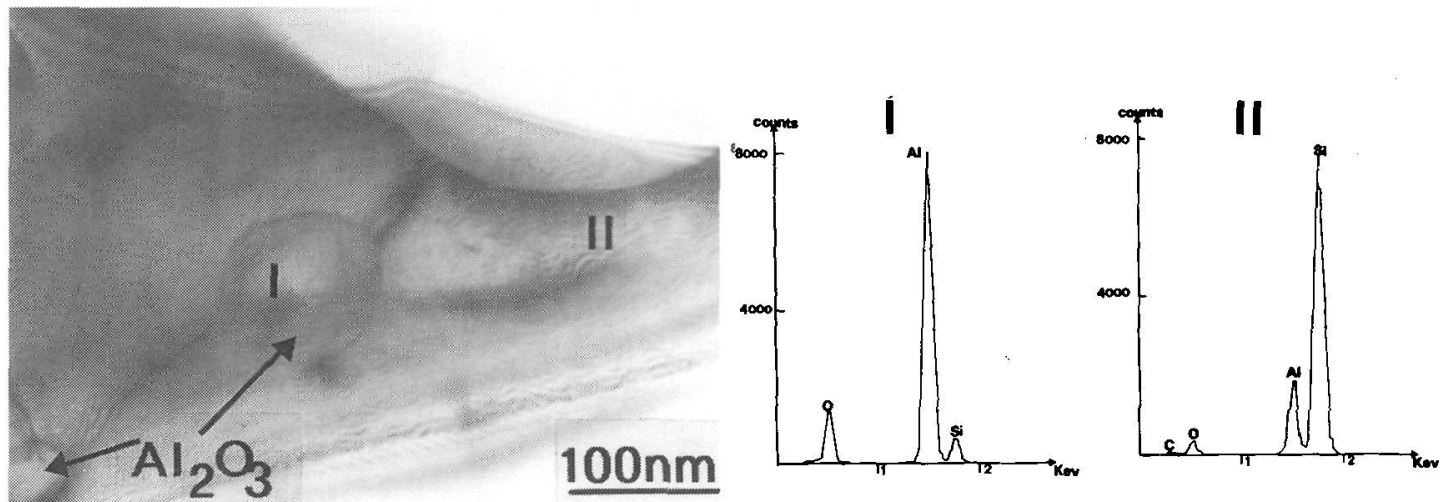

Fig. 1 : Aluminosilicate pocket with $\mathrm{Al}_{22} \mathrm{O}_{3}$ inclusions.
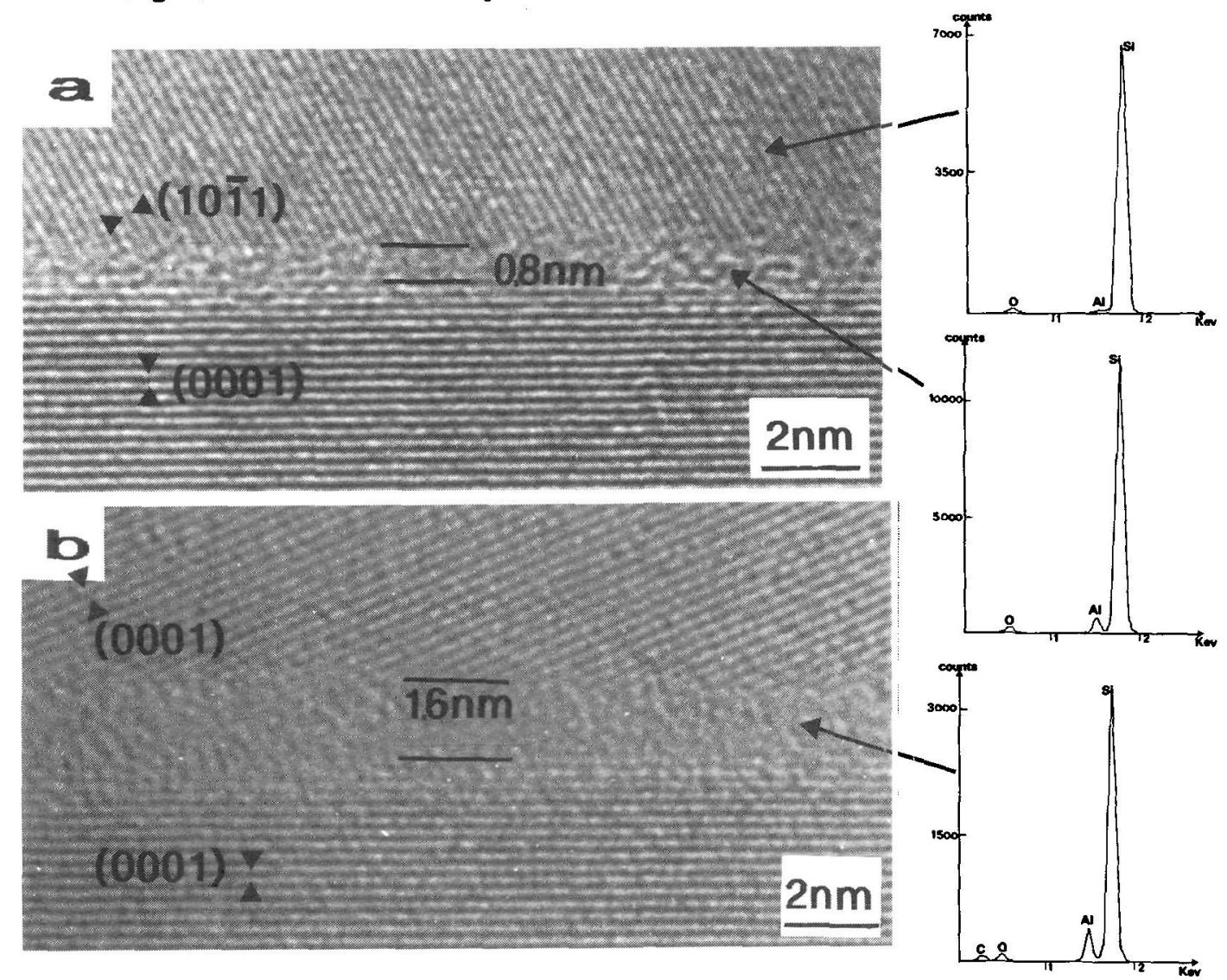

Fig. 2 : Lattice image revealing the presence of an amorphous intergranular film in sample \#3 (a) and in sample \#6 (b) 


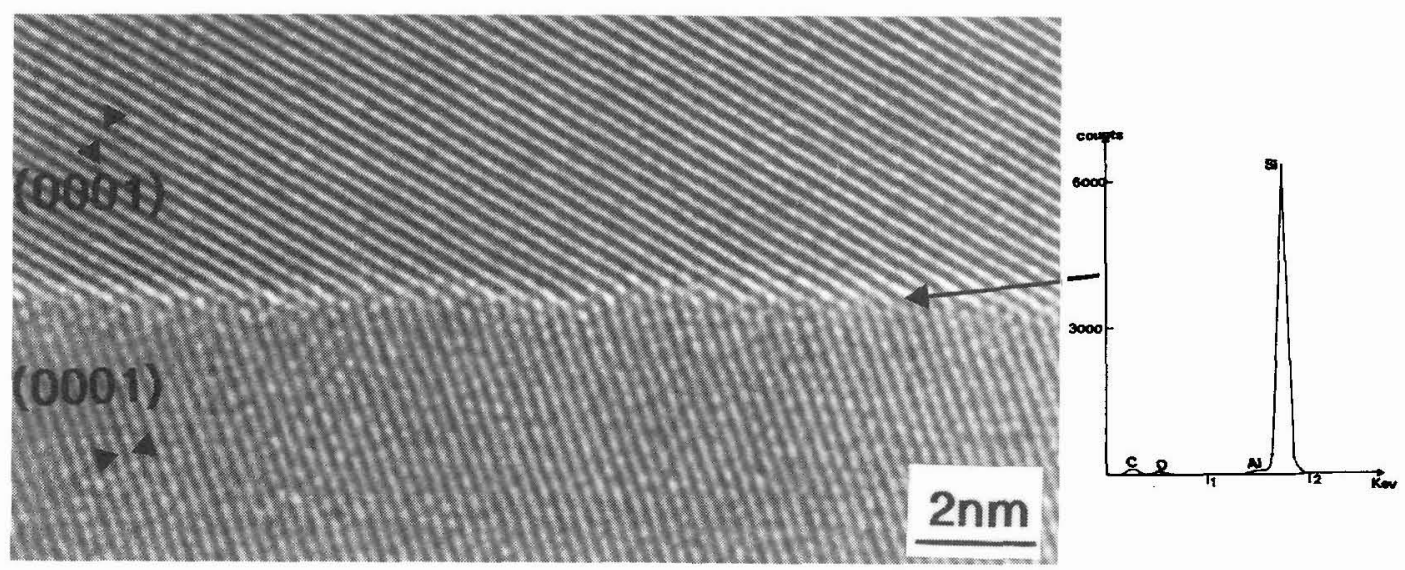

Fig. 3 : Example of a non-wetted grain boundary in sample \#4.

\section{DISCUSSION AND CONCLUSION}

Al/Si count ratio measured at g.b. of annealed and deformed specimens at $T>$ $1900^{\circ} \mathrm{C}$ is in agreement with the value already published for the same SiC grades [5]. However an amorphous intergranular film ( $\sim \mathrm{nm}$ thick) at SiC-SiC g.b. was clearly imaged in our case. Moreover the exact chemical composition of this aluminosilicate film remains undetermined. It can also be noticed that non-wetted g.b. which might correspond to low enegy g.b. [9] are rarely observed in as-sintered and annealed or deformed samples for the highest temperatures.

By contrast after three-point bending at $1600^{\circ} \mathrm{C}$ with a long time exposure, SiC-SiC grain boundaries are not wetted but only slightly segregated compared to the amount of impurities found in adjacent SiC grains. This loss of Al likely due to a $\mathrm{g}$. b. diffusion mechanism could be partly attributed to the long time exposure used in this experiment.

Further experiments with shorter time exposures at $1600^{\circ} \mathrm{C}$ will be carried out to explain the modification of the g.b. microstructure and the associated mechanisms.

\section{ACKNOWLEDGMENTS}

The authors would like to thank C.CARRY (EPFL Lausanne Switzerland) for providing crept SiC samples.

\section{REFERENCES}

[1] HAMMINGER R., GRATHWOHL G., and THÜMMLER F., J. Mater. Sci., 18 [10] (1983) 355.

[2] HAMMINGER R., GRATHWOHL G., and THUMMLER F., J. Mater. Sci., 18 [10] (1983) 3154.

[3] LANE J.E., CARTER C. H., and THÜMMLER F., J. Am. Ceram. Soc., 71 [4] (1988) 281.

[4] TAJIMA Y., and KINGERY W.D., Commun. Am. Ceram. Soc., 65 (2) (1982) C-27.

[5] TAJIMA Y., and KINGERY W.D., J. Mater. Sci., 17 (1982) 2289.

[6] KLEEBE H. J., J. Eur. Ceram. Soc, , 10 (1992) 151.

[7] SIGL L.S., and KLEEBE H. J., J. Am. Ceram. Soc., 76 [3] (1993) 773.

[8] CARRY C. and MOCELLIN A. in Materials Science Research Eds TRESSLER R.E. and BRADT R. C., Plenum Press, New York, 18 (1984) 391.

[9] CLARKE D.R., Mat. Sci. Res, edited by PASK J. A. and EVANS A.G., 21 (1986) 569. 